\title{
Signos de poder como marcadores del territorio hispano: una característica de la política urbanizadora de Augusto
}

\author{
Thomas G. SCHATTNER \\ Instituto Arqueológico Alemán de Madrid \\ thomas.schattner@dainst.de
}

\section{RESUMEN}

En época augustea no se observa la intención de colonizar toda Hispania, de ocupar sistemáticamente el territorio entero. Por el contrario, también las fundaciones augusteas, de forma similar a las cesarianas, parecen soluciones limitadas regionalmente y con visión de corto plazo, sobre todo como soluciones para problemas de organización interna, concretamente el licenciamiento de veteranos del ejército. Sin embargo Roma dominaba todo el país y especialmente a partir de la época de Augusto se empiezan a introduzir marcadores del poder en el territorio, los signos de poder. En el presente artículo se introduce este concepto (landmarks/Herrschaftszeichen) en el discurso científico hispánico. Son ellos las manifestaciones materiales del Imperio romano, especialmente en las provincias. Aunque el concepto sea extensible también a símbolos o textos, en el caso que nos interesa se refiere a arquitectura, monumentos, edificios. El término designa la calidad demostrativa del poder romano a través de una imponencia, originalidad y monumentalidad arquitectónica. Se trata de la señalización de la extensión territorial del imperio a través de monumentos dispersos en el territorio. Las arae sestianae, como las columnas de Hércules, son principalmente signos de poder que permiten referirse a los puntos extremos de la extensión del mundo en el discurso de un romano. El faro romano de La Coruña no sólo iluminaba el camino a los navegantes, sino que era, al mismo tiempo, una referencia cartográfica. Los signos de poder actúan para los dos lados: para los habitantes indígenas señalan la presencia de Roma como nueva potencia dominadora mediante un monumento físicamente existente, capaz de enaltecer el nuevo orden, siendo al mismo tiempo de una forma u otra útil, accesible y funcional. Para los romanos los signos de poder son un medio para entender mentalmente la extensión del imperio.

Palabras clave: Signos de poder. Augusto. Colonización. Territorio. Imperio.

\section{Landmarks as Symbols of Power: A Characteristic of the Urban Policy of Augustus}

\begin{abstract}
During the Augustan Age, there seems to be no intention of colonising Hispania as a whole, of systematically occupying the entire territory. Quite the opposite, Augustan settlements, very much like Caesarean settlements, seem to be solutions that are limited regionally and with a short-term perspective, an answer to internal organisational problems: more specifically, the discharging of army veterans. Nevertheless, Rome dominated the entire country and, especially from the Augustan Age onwards, Landmarks/Herrschaftszeichen were introduced in the territory as symbols of power. This article introduces the concept of Landmarks/Herrschaftszeichen in the Hispanic scientific discourse. They are the material manifestation of the Roman Empire, especially in the provinces. Although
\end{abstract}


this concept can be extended also to symbols or texts, in this case it will refer to architecture, monuments and buildings. The term references the demonstration of Roman authority through an imposing, original architecture that is monumental in nature. That is, the signposting of the Empire's territorial expanse through monuments that are spread across the territory. The Arae Sestianae, such as the Pillars of Hercules, are mainly symbols of power that afford a reference to the extreme confines to which the world spans in the discourse of any Roman citizen. The Roman lighthouse of La Coruña not only lit the way for seafarers; it was also a cartographical point of reference. Symbols of power act both ways. For indigenous populations they point to the presence of Rome as the new dominating power by means of a monument that is physically present and is capable of appraising the new order; at the same time, they are useful, accessible and functional in one way or other. For Roman citizens, these symbols of power are a means to mentally understanding how far their Empire extends.

Key Words: Landmarks/Herrschaftszeichen. Augustus. Colonization. Territory. Imperium.

La celebración de este Congreso sobre la Hispania de Augusto da pie para reconsiderar y revisar las distintas posiciones que la ciencia arqueológica ha ido adoptando a lo largo de un siglo con respecto al papel del primer princeps como fundador de ciudades en Hispania. Ante la extensión limitada del presente estudio, enfocamos el problema en algunos yacimientos de Occidente, destacando el desarrollo de la investigación en la Colonia Augusta Emerita, capital de la Lusitania, ya de por sí altamente idónea para esta reconsideración por ser tenida como la más augustea de las tres capitales provinciales de Hispania. ${ }^{1}$

Revisando la correspondiente bibliografía, se aprecian dos posiciones que se suceden en el tiempo. Mientras que desde el principio del siglo XX y hasta casi su final prevalecía de forma muy clara la idea de una planificación preconcebida de la ciudad, decidida de acuerdo con la nueva ideología augustea de la época y ejecutada en muy poco tiempo (Schulten, Mélida, García y Bellido, Álvarez Sáenz de Buruaga, Álvarez Martínez, Trillmich, Nogales Basarrate, Zanker y otros), actualmente, con la última generación se va imponiendo una visión más diferenciada gracias a los enormes esfuerzos de excavación e investigación desarrollados, dando como resultado que el papel del primer Princeps fue bastante más reducido debido a que los edificios en cuestión se datarían en fechas posteriores, o que su construcción acababa de comenzar, o que los edificios no se habían rematado (Bendala Galán, Mateos Cruz, Palma García, Ayerbe Vélez, Durán Cabello y otros). ${ }^{2}$ Frente a este panorama, el presente estudio pretende dar una rápida revisión de dichas posiciones, llegando a una conclusión puntualizada, contrastada con el concepto de imperium vigente en ese momento,

1 Trillmich 1990, 299. Como la temática abordada en el presente artículo es muy amplia y ha sido objeto de numerosos estudios, y tratándose, además, de una contribución a un congreso con las limitaciones de extensión normales, parece justificado mencionar sólo un número limitado de citas bibliográficas, que, en tanto, pueden parecer aleatorias. Agradezco a R. López Melero, a S. Panzram y a A. U. Stylow la disposición y amabilidad de aconsejarme en términos de bibliografía y otras cuestiones.

2 La opinión resumida se encuentra en MATEOS CRUZ 2001, 185, afirmándose que actualmente no existiría ningún edificio que se remontase más allá del cambio de era. Por último y resumiendo posiciones PANZRAM 2011,282 , n. 50 . 
el cual, a su vez, está íntimamente conectado con el entendimiento romano del espacio geográfico conquistado, que no es más que el orbis terrarum, es decir el mundo.

La contribución se divide en tres partes: primero se expone la cuestión de la fundación de ciudades en Hispania de forma diacrónica, mediante mapas de distribución que representan la situación en las sucesivas épocas, tal como se presenta desde los puntos de vista de la historia y de la arqueología, exponiendo a continuación de forma resumida los ejemplos de Mérida por un lado, como ciudad fundada ex novo, y de Conimbriga y Munigua como ciudades romanas superpuestas a poblados indígenas. Seguidamente se exponen las posiciones descritas, relacionando las aportaciones más significativas en un repaso historiográfico, llegando finalmente a una valoración en la que se destaca el papel de Augusto como impulsor de la construcción de templos y edificios públicos en determinados puntos de la geografía hispánica como signos de poder de Roma en la Península. El término se introduce aquí por primera vez en el lenguaje arqueológico español a partir de landmarks, Landmarke/Wahrzeichen, emblème.

\section{La distribución de colonias en la Península}

Cuando Cneo Cornelio Escipión desembarca con sus tropas en Ampurias en el año 218 a.C., se encuentra con un mosaico de tribus indoeuropeas en el oeste, el noroeste y en el centro de la Península, con iberos no indoeuropeos en la zona costera oriental y en el sur, y con grupos de población púnicos de las regiones costeras mediterráneas en el sur. Como es sabido, sólo al cabo de 200 años conseguiría Roma, por primera vez en su historia y mediante una persistente política de perfidia, brutalidad y hábil aprovechamiento de las disputas internas entre nativos (divide et impera), unificar este subcontinente europeo bajo una sola mano. Por primera vez será Augusto quien someta estos territorios tan dispares de Hispania a un nuevo orden caracterizado por basarse en principios iguales. ${ }^{3}$

El primer princeps, que pisó el suelo de la Península Ibérica por primera vez en el año 45 a.C. de la mano de César, quien acabaría por adoptarle gracias al trato más cercano que tuvo con su sobrino nieto, ${ }^{4}$ al final considera sus fundaciones de ciudades en Hispania suficientemente importantes como para recogerlas en la descripción de sus gestas (Res Gestae V 28): colonias in ...utraque Hispania ...deduxi. ${ }^{5}$ A continuación, nosotros nos planteamos brevemente dos cuestiones sobre: 1) las fundaciones augusteas según su significado en la política de asentamientos, y 2) según su importancia urbanística y, con ella, programática. Para la primera cuestión nos vamos a limitar a las colonias, pero en la segunda cuestión vamos a incluir los municipios.

\footnotetext{
3 Visiones generales: CURCHIN 1991; KoCH 1993.

4 CurChin 2001, 157; sobre el trasfondo de la estancia de Augusto en Hispania y su relación con la situación en la urbs, véase SCHMITTHENNER 1962.

5 WEBER 1974.
} 
Aquí resumimos en una tabla (tab. 1) las fundaciones romanas de colonias. El catálogo se debe a Antonio García y Bellido, la datación se basa en las investigaciones de Hartmut Galsterer. ${ }^{6}$

\section{Tabla 1}

\begin{tabular}{|c|c|c|c|c|}
\hline \multicolumn{5}{|c|}{ Colonias romanas en Hispania } \\
\hline $\begin{array}{l}\text { Pre-cesari- } \\
\text { anas } \\
\end{array}$ & Cesarianas & \begin{tabular}{|l}
$\begin{array}{l}\text { Post-cesarianas/ } \\
\text { Pre-augusteas }\end{array}$ \\
\end{tabular} & Augusteas & Post-augusteas \\
\hline $\begin{array}{l}\text { Col. Latina } \\
\text { Libertinorum } \\
\text { Carteia }\end{array}$ & $\begin{array}{l}\text { Col. Urbs Tri- } \\
\text { umphalis Tarra- } \\
\text { conensis }\end{array}$ & $\begin{array}{l}\text { Col. Urbs Nova } \\
\text { Carthago }\end{array}$ & $\begin{array}{l}\text { Col. Iulia Gemellia } \\
\text { Accis }\end{array}$ & $\begin{array}{l}\text { Col. Iulia Augusta Der- } \\
\text { tosa }\end{array}$ \\
\hline $\begin{array}{l}\text { Ilurcis/Grac- } \\
\text { curis }\end{array}$ & Hasta Regia & $\begin{array}{l}\text { Col. Victrix Iulia } \\
\text { Lepida/Col. Vi- } \\
\text { ctrix Iulia Celsa }\end{array}$ & $\begin{array}{l}\text { Col. Caesarina Au- } \\
\text { gusta Asido }\end{array}$ & Col. Clunia Sulpicia \\
\hline $\begin{array}{l}\text { Col. Patricia } \\
\text { Corduba }\end{array}$ & $\begin{array}{l}\text { Col. Iulia Romu- } \\
\text { la Hispal }\end{array}$ & \begin{tabular}{|l|} 
Col. Norbensis \\
Caesarina \\
\end{tabular} & $\begin{array}{l}\text { Col. Augusta Firma } \\
\text { Astigi }\end{array}$ & Flaviobriga \\
\hline Palma & $\begin{array}{l}\text { Col. Claritas Iu- } \\
\text { lia Ucubi }\end{array}$ & & $\begin{array}{l}\text { Col. Faventia Iulia } \\
\text { Augusta Paterna } \\
\text { Barcino }\end{array}$ & $\begin{array}{l}\text { Col. Aelia Augusta Vi- } \\
\text { ctrix/Urbs Italica }\end{array}$ \\
\hline Valentia & \begin{tabular}{|lr} 
Col. & Genetiva \\
Iulia & Urbanorum \\
Urso & \\
\end{tabular} & & $\begin{array}{l}\text { Col. Caesar Augus- } \\
\text { ta }\end{array}$ & $\begin{array}{l}\text { Iulia } \quad \text { Traducta/Iulia } \\
\text { Ioza? }\end{array}$ \\
\hline \multirow[t]{5}{*}{ Pollentia } & Emporiae? & & $\begin{array}{l}\text { Col. Augusta Eme- } \\
\text { rita }\end{array}$ & \\
\hline & Col. Metellensis & & $\begin{array}{l}\text { Col. Iulia Ilici Au- } \\
\text { gusta }\end{array}$ & \\
\hline & Pax Iulia & & $\begin{array}{l}\text { Col. Libisosa Fo- } \\
\text { rum Augustana }\end{array}$ & \\
\hline & $\begin{array}{l}\text { Scallabis Praesi- } \\
\text { dium Iulium }\end{array}$ & & Salaria & \\
\hline & & & $\begin{array}{l}\text { Col. Augusta Ge- } \\
\text { mella Tucci }\end{array}$ & \\
\hline
\end{tabular}

Primero hay que destacar que en este cuadro dividido en épocas resulta bastante uniforme la cantidad de fundaciones de colonias. Sin embargo, la época precesarea abarca un largo periodo de casi dos siglos, desde la primera colonia de Carteia en el 171 a.C. hasta la de Pollentia antes del 123/122 a.C. Por lo demás, la cantidad de fundaciones en la época cesariana y en la época augustea se mantiene igualada y en la época post-augustea se reduce.

Veamos las fundaciones precesareas (Fig. 1). Con el trasfondo político de un país posiblemente no pacificado del todo, estas primeras fundaciones se debieron, por lo que parece, a decisiones tomadas a corto plazo como resultado de circunstancias problemáticas en la política cotidiana, surgidas de situaciones concretas originadas por la guerra en cada caso. No hay que olvidar que la Península no se conquistó de una sola

6 García y Bellido 1959; García y Bellido 1966, 34 s. 176; Galsterer 1971, 65-72. 


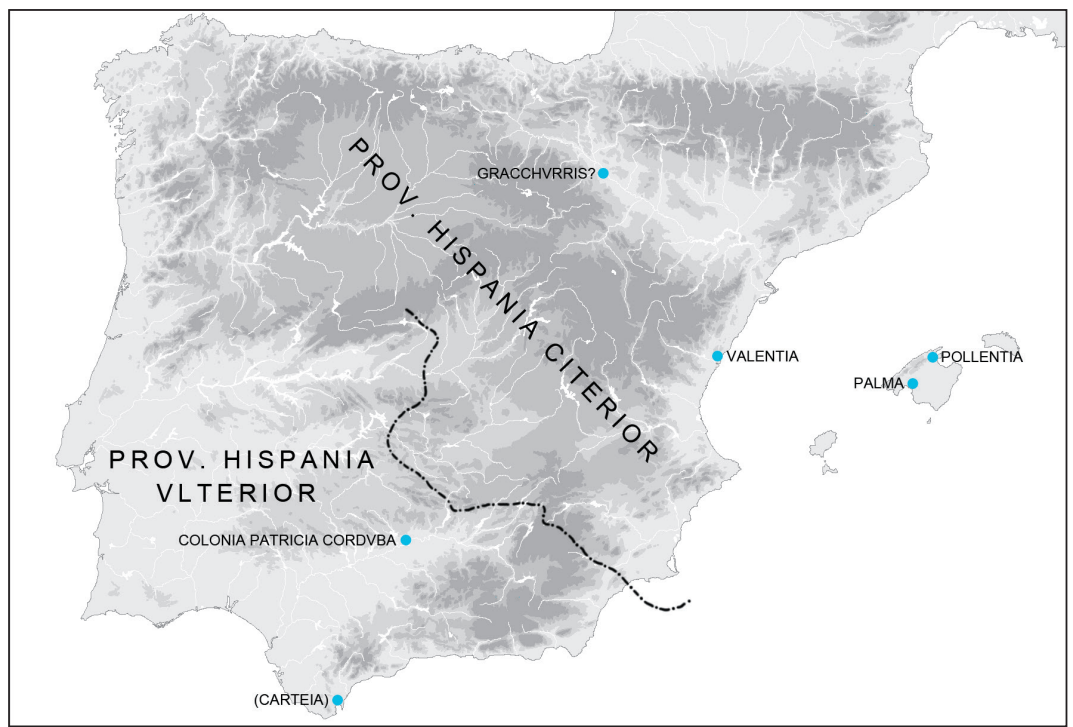

Fig. 1. Fundaciones precesareas. IAA de Madrid (E. Puch Ramírez).

vez, sino por medio de numerosas batallas extremadamente duras. ${ }^{7}$ En consecuencia, la colonización romana se desarrolla con titubeos, con una casuística diferente en cada región y de manera desigual. No sigue ningún modelo unitario, ni en su aplicación técnica de la administración ni en su situación geográfica. Carteia, la colonia más antigua, es un caso aislado, pues con ella se acalló a los hijos nacidos de la unión de mujeres nativas con soldados romanos que reclamaban el derecho de ciudadanía íntegro bajo el derecho latino y la concesión de Carteia como hogar familiar. ${ }^{8}$ Sólo a finales del siglo II a.C., bajo la presión de los colonos itálicos que se trasladaron a Hispania, ${ }^{9}$ se produce una dinámica mayor que, sin embargo, sólo llega a desarrollarse plenamente tras la guerra civil entre César y Pompeyo en la época julio-claudia, dado que la mayor parte del país estaba pacificado. Al contrario de lo que hizo en Italia Central y en la Galia Cisalpina, al principio Roma actúa en Hispania sin un concepto claro, la visión a largo plazo sólo empieza a plantearse a lo largo del siglo II a.C., y a aplicarse en época cesariana, ${ }^{10}$ como se detalla en el siguiente párrafo. Las

7 Véase al respecto el mapa en Koch 1993, 13 fig. 2.

8 LAFFi 2002.

9 Emigración desde Italia y deportaciones dentro de la misma Península Ibérica se constatan desde los primeros momentos de la conquista romana, pero especialmente después de la guerra contra los celtíberos y los lusitanos a finales del siglo II a.C., con certeza motivada por la existencia de minas y de las correspondientes perspectivas económicas, véase Diodoro, 5.36.3-4 y la bibliografía: BLÁzQUEZ MARTíNEZ - DOMERGUE - Sillières 2002, 386 s. 394 con nota 66; Pina Polo 2004; Pina Polo 2007, 38-40; Pina Polo 2009; Pina Polo $2010,76$.

10 RoDÁ 1997; LAFFI 2002. 
colonias se encuentran en la costa o en el interior y los colonos son en su mayor parte soldados, como en Carteia o Graccurris, ${ }^{11}$ o veteranos, como en Corduba. ${ }^{12}$

Para responder a la segunda cuestión planteada, abrimos un paréntesis para exponer la situación de las ciudades, que no colonias, en el valle del Ebro en el siglo II a.C. tardío y principios del siglo I a.C. Analizándolas, F. Pina Polo observó una cierta regularidad en la fundación de nuevas ciudades romanas a no mucha distancia, de 4 a $8 \mathrm{~km}$, del correspondiente poblado indígena. Destacan por el hecho de mantener el nombre del poblado indígena. Este autor considera que con el mantenimiento del nombre se trata de sugerir una continuidad, algo que de hecho no se da, ya que se trata de fundaciones nuevas. El urbanismo está adaptado a los condicionantes del terreno, de modo que no son ciudades con sistema viario ortogonal; en esto, las fundaciones del valle del Ebro se distinguen, parcialmente, de las fundaciones de la Bética. ${ }^{13} \mathrm{El}$ área del valle del Ebro, mejor dicho su hinterland meseteño, vuelve a despertar nuestro interés en época cesarea (Fig. 2), cuando se observa toda una serie de fundaciones nuevas y contemporáneas todas ellas, hecho que llevó a calificar dicha circunstancia de medida programada. ${ }^{14}$

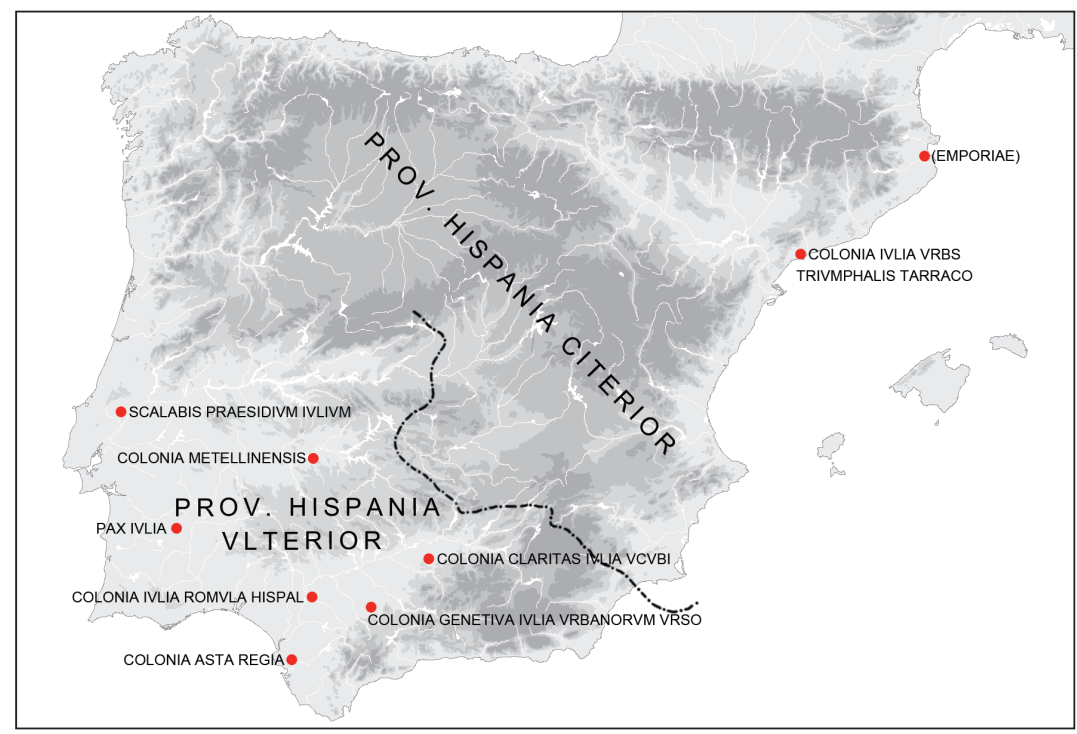

Fig. 2. Fundaciones de época cesarea. IAA de Madrid (E. Puch Ramírez).

Volviendo a las colonias, sobre la fundación de Urso sabemos que los colonos procedían del proletariado de Roma, ${ }^{15}$ mientras que en Hispalis vuelven a ser militares. ${ }^{16}$

11 García y Bellido 1959, 450.

12 BlázQuez 1976, 104.

13 Pina Polo 1993.

14 Pina Polo 1993, 92.

15 BlázQuez 1976, 98. 104.

16 BlázQuez 1976, 104. 
Su fundación pudo basarse en consideraciones geoestratégicas, tratando de ocupar la desembocadura del Guadalquivir con una ciudad en el interior del Lacus Ligustinus, es decir, con el puerto necesario para la exportación del aceite de oliva. Incluso Regia parece haber tenido importancia en la época prerromana, puesto que allí "se solían reunir los gaditanos", como informa Estrabón (III 2.2). El papel pionero de Tarraco en la costa mediterránea es evidente, teniendo en cuenta que Augusto permaneció allí dos años al comienzo de la campaña cántabra (26/25 a.C.).

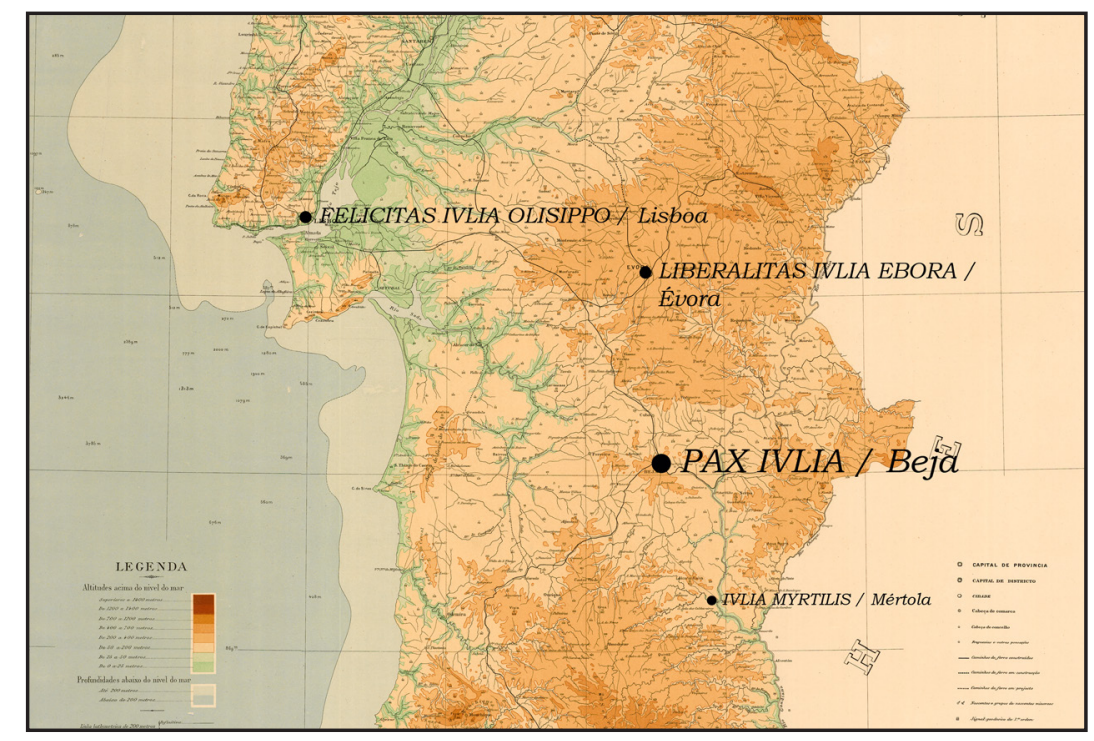

Fig. 3. La colonia de Pax Iulia, acompañada por los municipios de Ebora y Olisippo y la comunidad peregrina de Myrtilis en el sur de Lusitania. IAA de Madrid (E. Puch Ramírez).

Las decisiones necesarias para fundar ciudades, sin embargo, parece que continúan siendo puntuales, debiéndose a las circunstancias del momento. También se constata un elemento nuevo, un plano programático y jerárquico a nivel regional, como muestra el ejemplo del sur de Lusitania (Fig. 3), un territorio que tradicionalmente, y hasta el cambio de era, fue objetivo de bandas de ladrones y merodeadores movidos por el ansia de botín. ${ }^{17}$ Aquí surge una red de núcleos urbanos con Pax Iulia como colonia, acompañada por las dos ciudades de Ebora y Olisippo como municipios y, finalmente, Myrtilis como comunidad peregrina, red que los investigadores luso-franceses han reconocido como consecuencia de una planificación intencionada para dotar al sur de Lusitania de un hábitat seguro por medio de la fundación de estas ciudades, y así proporcionar un hogar familiar a todos los grupos de población. ${ }^{18} \mathrm{La}$ intencionalidad programática se refleja hasta en los nombres elegidos para estas poblaciones, Pax, Felicitas y Libertas Julia, que se corresponden con eslóganes ideológicos, y en el

17 WAHL 1985, 169-173.

18 Alarcão - Étienne 1976, 173. 
esquema jerarquizado de estas ciudades situadas en torno a una capital, en este caso Pax Iulia/Beja, en función de la cual existen; en ello hay que reconocer un elemento típicamente hispánico del que se carece en Italia. ${ }^{19}$

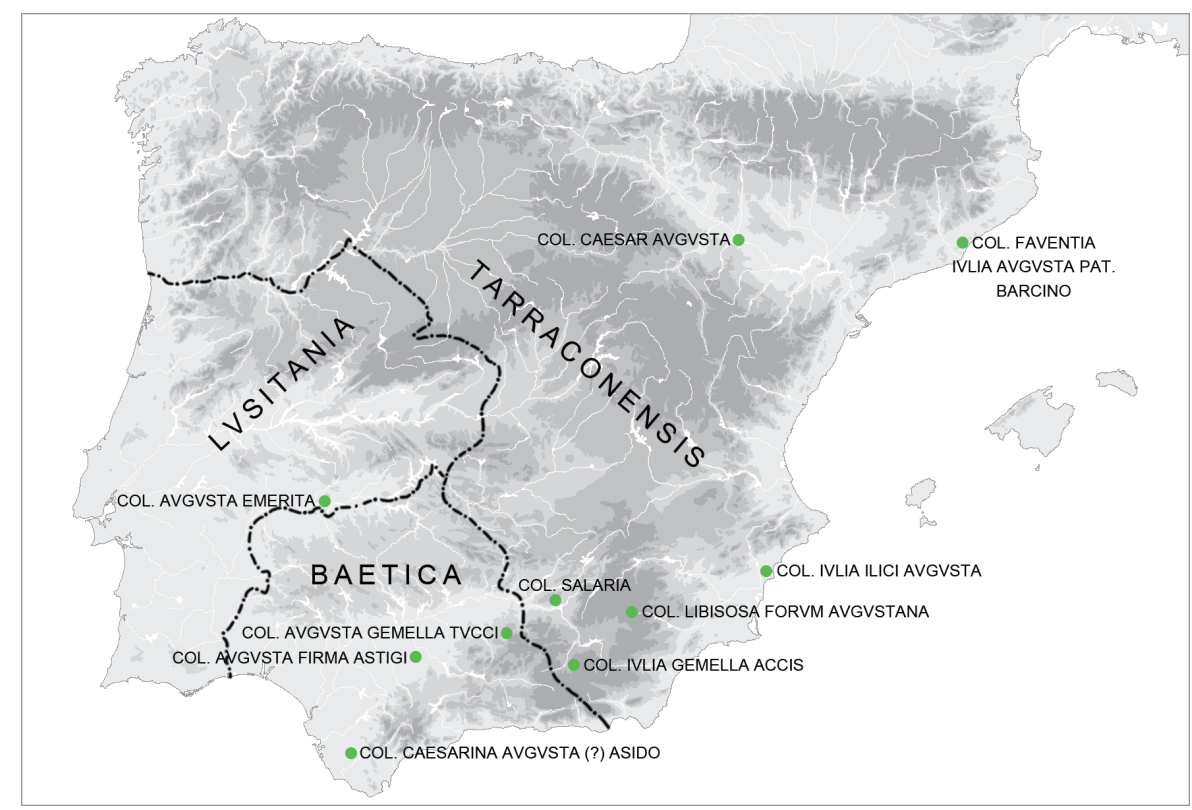

Fig. 4. Fundaciones de época augustea. IAA de Madrid (E. Puch Ramírez).

Llegando a la época augustea se observan más criterios para la ubicación de ciudades, destacándose ahora su carácter infraestructural (Fig. 4). Así, las ciudades se construyen en vados, como Caesaraugusta o Augusta Emerita, y al mismo tiempo se amplía el sistema de carreteras, desde luego sobre las rutas ancestrales, conservándolas. ${ }^{20}$ Parece que el leitmotiv fue el interés por una mayor exploración y urbanización del país. Como muy tarde es a partir de ese momento cuando Roma estuvo en posesión de un cierto conocimiento del terreno hispano, como demuestra, hasta cierto punto, la elaboración del orbis pictus en Roma, un panel elaborado por Agripa (Plin., NH III 16-17; IV 118), de cuyo aspecto, dimensión o contenido directamente no se sabe nada, aunque todo indica, que no parece haberse tratado de un mapa, sino más bien de una inscripción con un texto geográfico del mundo, poco más que un listado con nombres de continentes, mares, provincias y saltus, con indicaciones de algunas distancias. ${ }^{21}$ Además, ese aumento del conocimiento del territorio se reconoce en el lenguaje de la época, observándose un cambio en la terminología técnica y política correspondiente, es decir, orbis terrarum por un lado e imperium romanum por el

\footnotetext{
19 ZANKER 1990, 22.

20 Alarcão - Étienne 1976, 176-178; Corzo Sánchez 1976; Bendala 1990, 38 ss.

21 BRODERSEN 1995, 268-287 con el intento de reconstrucción en pág. 286 Abb. 43 mostrando una inscripción de 18 líneas.
} 
otro. Hay que aclarar que durante la época republicana el concepto romano de la forma y orografía de los territorios conquistados, es decir, de su imperio territorialmente entendido, era bastante incompleto más allá de la capital de Roma y del Lacio. El imperium, como término, era el poder administrativo más absoluto, concedido por el Senado a altos funcionarios del Estado (praetores), el imperio proconsulare acabó siendo la base jurídica para el mando militar del Emperador en las provincias fronterizas. Sólo a finales del s. II a.C. se observa que los correspondientes términos imperium y provincia empiezan a tener una connotación territorial al referirse a zonas bajo control romano. Sin embargo, ese proceso fue lento, y todavía los autores de finales de la República, como Cicerón, entendieron el término imperium como un control no específico que se extendía sobre todo el orbis terrarum, es decir, el control sobre un imperio mundial ilimitado en su extensión (Cic., off. 2.26-28). ${ }^{22}$ En la época augustea la terminología se amplía semánticamente en el sentido descrito, y tanto imperium como provincia adoptan una dimensión territorial, de tal forma que imperium ahora supone un contenido geográfico con las provincias como entidades territoriales, es decir, con una división interna del término, que pasa a ser un término genérico, un concepto general territorialmente hablando. Consecuentemente, aparecen expresiones como corpus imperii (Ov., Trist. 2.231-2), pars imperii (Vell. Pat., 2.97.1; Tac., Agr. 24.1; Suet., Aug. 48) y otros más. ${ }^{23}$

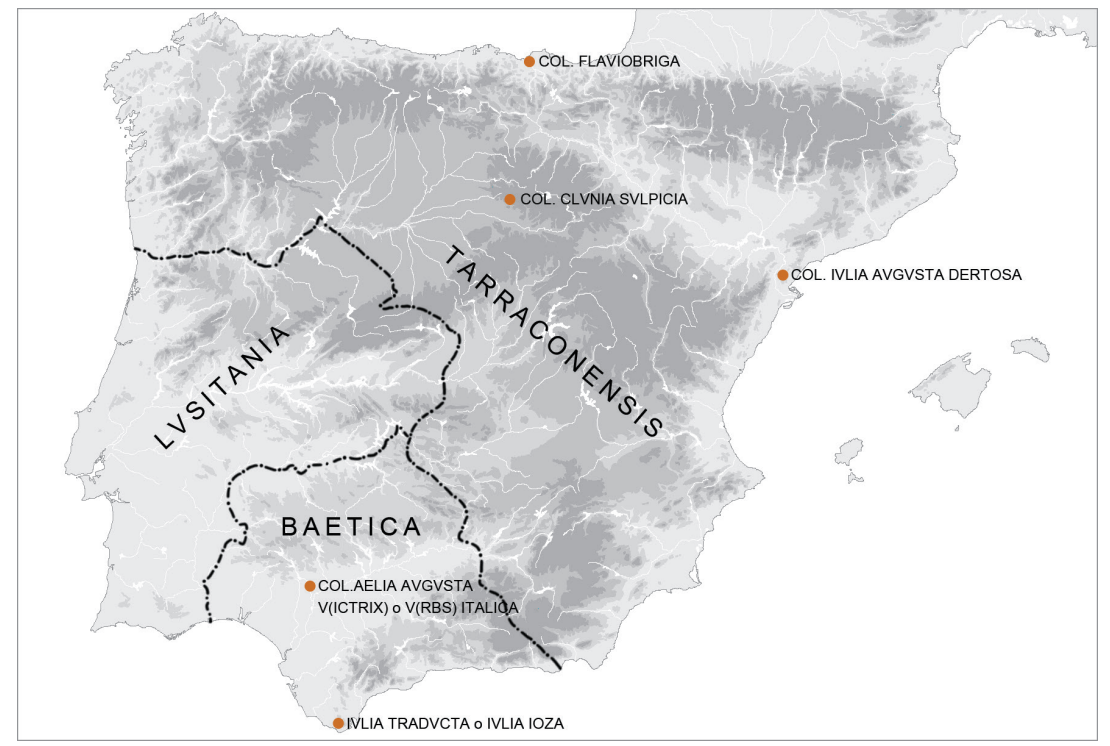

Fig. 5. Fundaciones de época postaugustea. IAA de Madrid (E. Puch Ramírez).

22 BENDLIN 1997, 36-38.

23 Estas cuestiones se vienen discutiendo desde el s. XIX, véase BLEICKEN 1967; importante es el estudio de Millar 1988 y los resúmenes de Kienast 450f. 500 y Bendlin 1997, 36-38. 
De todos modos, en época augustea no se observa la intención de colonizar todo el país, de ocupar sistemáticamente el territorio entero. Por el contrario, también las fundaciones augusteas, de forma similar a las cesareas, parecen soluciones limitadas regionalmente y con una visión a corto plazo, sobre todo como una solución para problemas de organización interna, concretamente para el licenciamiento de veteranos del ejército. ${ }^{24}$ Ya en la época posterior a Augusto (Fig. 5) apenas hay noticias sobre la llegada de colonos, y las pocas colonias sirven para atender a los veteranos. ${ }^{25}$

El conjunto irregular de las fundaciones de colonias romanas en la Península Ibérica (Fig. 6) se explica por las descripciones, como hemos visto. Si cambiamos el enfoque e incluimos también los municipios, la conclusión es parecida. Así, en algunas regiones, como en la Bética, las ciudades y los asentamientos se acumulan, mientras que en otras regiones, como en la Meseta Central hispana, faltan por completo las ciudades en amplias áreas. En un país que debido a su extensión, con más de 1.000 $\mathrm{km}$ en cada dirección, constituye un verdadero subcontinente europeo, esta colonización irregular y no equilibrada resulta tanto más sorprendente.

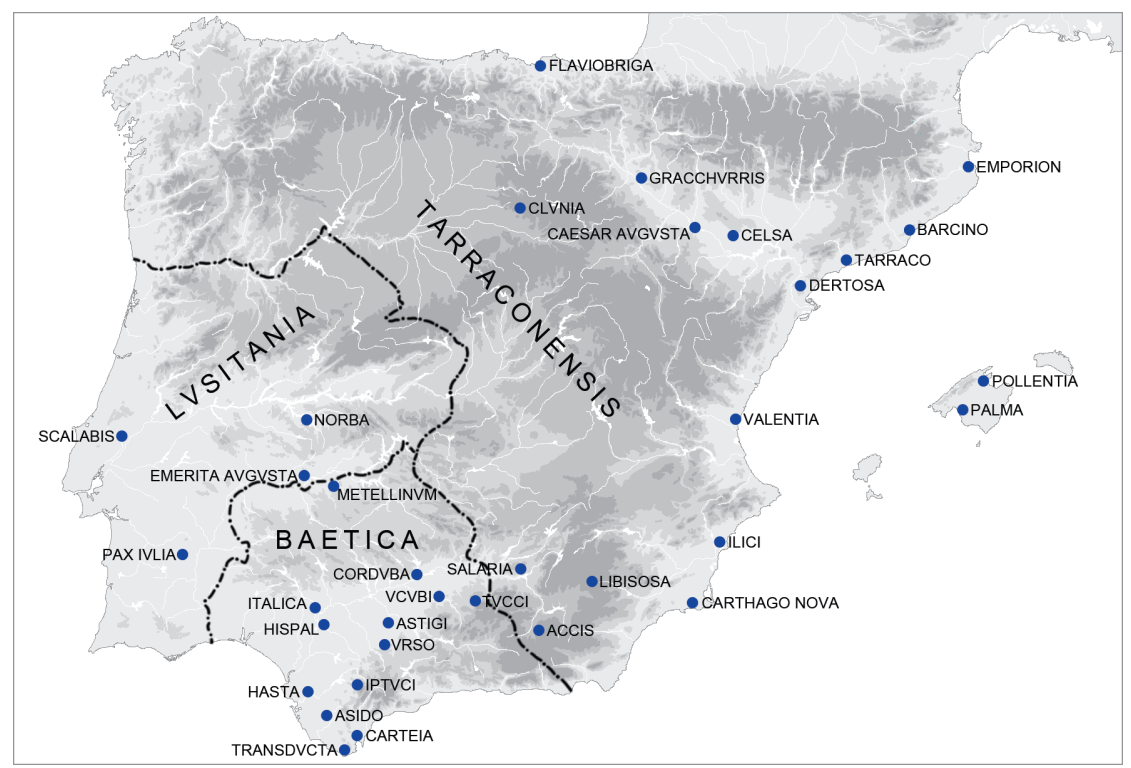

Fig. 6. Fundaciones de colonias romanas de todas las épocas. IAA de Madrid (E. Puch Ramírez).

La conquista romana de la Península Pirenaica terminó definitivamente en el año 19 a.C., con el final de las guerras cántabras, y a continuación se establece en las provincias occidentales del Imperio Romano una forma de convivencia hasta entonces desconocida: la ciudad, en la que cada vez se diferencian más los ámbitos de lo

24 BALIL 1976, 74.

25 BlÁzquez 1976, 136. 
público y lo privado, lo sagrado y lo profano, el trabajo y la vida personal, en la que las manifestaciones vitales de las personas se compactan de una forma nueva, en la que surgen formas propias de vida (vida urbana). ${ }^{26}$ Con la fundación de ciudades en los territorios conquistados, las futuras provincias, Roma responde a la necesidad de administración. Las ciudades, esto es, las instituciones asentadas allí, aseguraban el cumplimiento del derecho romano y sus funcionarios lo aplicaban (Estrab., III 2). La digresión histórica es necesaria porque sólo así se puede calcular la dimensión de lo que los romanos trajeron a la Península en forma de comunidad de la ciudad romana. Si se considera la política romana de asentamientos en su conjunto, ésta se manifiesta urbanísticamente sobre el trasfondo de la evolución histórica como:

- Construcción de una ciudad y de sus edificios en el lugar de los asentamientos existentes, es decir, los autóctonos prerromanos. En estos casos, la estructura de la ciudad muestra trazados de calles que se orientan según el terreno con construcciones irregulares, donde aparecen edificios romanos aislados, en general de carácter público. Dado que los asentamientos autóctonos se encuentran casi siempre en sitios elevados, estas ciudades suelen presentar un declive en el terreno, ejemplos de este tipo son Bilbilis en la Tarraconense o Munigua en la Bética.

- La construcción totalmente nueva de ciudades como asentamientos en llano sobre terrenos previamente libres de núcleos habitados, como es el caso del Valle del Ebro, por ejemplo. ${ }^{27}$ En estos casos, las ciudades suelen tener la forma de la ciudad romana regular, que basa su estructura urbanística en el Cardo y el Decumanus. No se conoce la cantidad total, esto es, la relación entre los asentamientos en llano y en altura. Roma fundará en Hispania 400 ciudades, aproximadamente una quinta parte de todas las ciudades existentes en el Imperio Romano. ${ }^{28}$

De ello resulta jurídicamente que no todas las fundaciones de colonias son de nueva construcción; no tuvo que producirse necesariamente una deductio de colonos, sino que puede tratarse de fundaciones honoris causa. ${ }^{29} \mathrm{Es}$ decir, al contrario de lo que sucedió en Germania o en Britania, las fundaciones de ciudades en Hispania no surgieron de los campamentos militares romanos.

A disposición de los colonos se pusieron tierras, agua y posiblemente las casas, ${ }^{30}$ aunque también hay que pensar en una dotación mínima de infraestructura edilicia pública, tal como lo demuestra la conocida inscripción de Munigua, por la que un tal Lucio Valerio Firmo, de la tribu Quirina, dedicó un templo, un foro, un pórtico y una biblioteca/archivo. ${ }^{31}$ Pero también el mismo Augusto actuó varias veces como benefactor en ese sentido. ${ }^{32}$ Para su levantamiento se puede pensar en la utilización del ejército. ${ }^{33}$ Sin embargo, para el funcionamiento regulado de una ciudad era con-

26 Sobre las diferentes concepciones de ciudad, véase p. ej. Burillo Mozota 2007, 251-267.

27 Burillo Mozota 2007, 315-326.

28 BOATWRight 1997, 119; BoATwright 2000.

29 BALIL 1976, 57-73. De hecho, la cantidad de colonias honoríficas crece a lo largo del tiempo, mientras que la cantidad de fundaciones nuevas se va reduciendo. Sobre esto véase también BLÁzQUEZ 1976, 136.

30 BALIL 1976, 57.

31 Estado actual de la investigación en ScHATTNER 2013.

32 Ejemplos en Kienast 1999, 420 ss.

33 NünNerich-Asmus 1993, 140; KienAST 1999, 448; RodÁ 1997; Horster 2001, 168-187. 
dición necesaria la instalación y equipamiento de las mismas con las construcciones necesarias, concretamente el foro y las edificaciones correspondientes, tales como templos, santuarios, basílica y curia, con frecuencia también combinadas con unas termas en las proximidades. Estos edificios tenían que estar patrocinados. Señalamos el modelo ideal de Augusta Emerita, la capital de Lusitania, en un dibujo esclarecedor de Jean-Claude Golvin, que reproduce el estado de una ciudad acabada. ${ }^{34}$ ¿Cuánto de ello se produce en la época augustea? Asombrosamente poco. Los motores de la construcción de ciudades, tales como la división del trabajo y la jerarquía social, la generosidad, el instinto paternal de los benefactores, el bienestar, el ideario de carrera política y el oportunismo, no son fenómenos simultáneos, sino que deben ir cristalizando paulatinamente. También los funcionarios de la administración estatal, tales como legados imperiales o procónsules, deben primero ocupar su residencia en las ciudades de nueva fundación, y su establecimiento definitivo llevará, en un segundo paso, a la construcción de las correspondientes viviendas, y a su derecho a un equipamiento adecuado de los edificios públicos y también de los templos. ${ }^{35}$

\section{El ejemplo de la Colonia Augusta Emerita como fundación ex novo}

Como ejemplo consideremos brevemente la situación actual en la Colonia Augusta Emerita. Tradicionalmente, como primeras construcciones de época fundacional ${ }^{36}$ se solían mencionar: el puente, la correspondiente puerta occidental de la ciudad ("Puerta del puente"), el teatro y el anfiteatro, así como el llamado Templo de Diana y el Foro. ${ }^{37}$ Mientras que para los edificios de espectáculos se conservaron las correspondientes inscripciones, que permitieron identificar a Agripa como el fundador y promotor del teatro, cuya inscripción pavimental data del año 16 a.C. ${ }^{38}$ y asimismo la inscripción de Augusto del anfiteatro, que permitió fechar el edificio hacia el año 8/7 a.C. ${ }^{39}$ para las edificaciones de uso práctico, como el puente y la puerta, los criterios de datación han sido técnicos ${ }^{40}$ tipológicos ${ }^{41}$ y estilísticos, ${ }^{42}$ es decir, son de carácter más general, ya que no permiten dataciones demasiado concretas. ${ }^{43}$ Hoy en día, con

34 Golvin 2006, 124 ss.

35 BALIL 1976, 8.

36 La fundación de Augusta Emerita relatada por Dio Cassio, Hist. Rom. LIII 25.8-26.1.

37 TRILlMich 1990, 302-310.

38 Sobre ese año la ciudad parece haber ascendido a capital de la recién creada provincia lusitana, y adquirido su conocido nombre de Colonia Augusta Emerita, véase RodDAZ 1993.

39 Trillmich 1990, 304 ss; Durán 2004, 60.

40 Por la manera de encaje de los bloques cuneiformes de las arquivoltas, TriLlmich 1990, 304; NüNNERICH-ASMUs 1990, 143.

41 Por los pequeños arquillos de aligeramiento, NÜNNERICH-Asmus 1990, 143.

42 Pfanner 1990, 104 fig. 34 (Guadiana).

43 De hecho, J. M. Álvarez (Álvarez Martínez 2006, 242-250) no adelanta fechas propias en su estudio de la Puerta del Puente, teniendo para ello que recurrir a la analogía con las monedas de época fundacional. En relación a la perduración de técnicas edilicias bastará señalar, a título de ejemplo, que los sillares almohadillados, considerados augusteos, de la Puerta del Puente de Mérida aparecen de la misma forma en el Templo romano de Sant'Ana do Campo, en la vecina región portuguesa del Alentejo, fechado en el siglo II d.C. avanzado, véase SchatTNER 1999, 196 fig. 2 láms. 37, 39, 44, 45; p. 214. 
el estado del saber actualizado, hay que constatar que las inscripciones de las dos edificaciones para espectáculos se refieren a las primeras fases constructivas en el caso del anfiteatro o a la fecha de la inauguración del teatro, momento en el que la obra se encontraba en pleno desarrollo. ${ }^{44}$ Para la construcción de las murallas y de sus accesos, sin embargo, se suele admitir para los lienzos norte y oeste, al menos de un modo general, una fecha en época augustea. ${ }^{45}$ Con este trasfondo adquiere importancia la observación de que las monedas romanas en general muestran con frecuencia edificaciones públicas en el reverso. ${ }^{46}$ Como ejemplo concreto valgan algunas monedas tempranas de Augusta Emerita con la representación de una puerta de la ciudad y un templo de cuatro columnas. ${ }^{47}$

Además, dichas dataciones se ven dificultadas por las muchas fases de construcción, de renovación y de restauración que presentan estas edificaciones, sin embargo no dejan de marcar el contexto cronológico indicado. ${ }^{48}$ Pero también para los mencionados edificios del teatro y del anfiteatro se piensa en un periodo prolongado de ejecución de la obra. ${ }^{49}$ De hecho, los últimos datos apuntan a que este primer teatro debió de estar en construcción durante la época augustea, según la información que proporcionan los capiteles de las scaenae frontes, prolongándose la obra por lo menos hasta la época de Claudio, cuando el edificio debió de haber alcanzado cierta altura e incluso haber sido operativo. ${ }^{50}$ También en época posterior, domicianea, ${ }^{51} \mathrm{se}$ constatan actuaciones de construcción y de reforma que se deben de haber prolongado a la época trajanea ${ }^{52}$ y que le dieron el aspecto que tiene hoy en día. El periodo de construcción del anfiteatro fue más corto, aunque seguramente no estuvo acabado antes del año 16/15 a.C. y sus obras debieron de prolongarse más allá de la muerte de su fundador en el año 12 a.C. ${ }^{53}$ En los mismos términos puede describirse el levantamiento del Templo de Diana, fechado en época augustea o julio-claudia temprana. ${ }^{54}$ Ya el complejo arquitectónico del Foro de mármol, originalmente tenido como de época julio-claudia, se ha datado en época flavia ${ }^{55}$ basándose en los últimos estudios que se han realizado de su decoración arquitectónica y de su escultura.

Con estas obras, la mayor parte de ellas de larga duración, contrasta el ejemplo del Templo a cella barlonga de la c/Holguín, cuyas obras se desarrollaron en sólo cinco

44 Anfiteatro: Bendala Galán - Durán 1994; Mateos Cruz 2001, 202. Teatro: Mateos Cruz - MáRQuez 1999; Durán CABello 2004, 57. Ya en el año 1913 Macías Liañez pensaba en una construcción de piedra para los asientos de los espectadores, y unas scaenae frontes de madera (MACíAs LiAÑEZ 1913, 89).

45 Mateos Cruz 2001, 187ss; Mateos Cruz 2004, 30.

46 BALIL 1976, 69.

47 Mora 2004, 19 fig. 4. Sobre el papel de las monedas como documento de la fundación de la colonia, véase Trillmich 1990, 300-302, sobre las correspondientes acuñaciones por último CeBrián SÁNCHEZ 2008, 247 ss.

48 Puente: Álvarez Martínez 1983, 49-58; puerta: Álvarez Martínez 2006, 235-242.

49 Trillmich 1990, 305.

50 DURÁN 2004, 57.

51 Stylow - Ventura Villanueva 2009, 522.

52 Stylow - Ventura Villanueva 2009, 522.

53 TRILlmich 1990, 305.

54 Álvarez Martínez - Nogales Basarrate 2003, 286-290; Mateos Cruz - Palma García $2004,43$.

55 PeÑa 2009a, 568-582; PeÑa 2009b, 599. 
años (25-30 d.C.). ${ }^{56}$ La gran diferencia de los periodos de construcción es llamativa y permite extraer conclusiones. Así, la razón del tiempo empleado en las correspondientes edificaciones parece derivar de la importancia de cada una de ellas. De este modo, la rapidez en la construcción del Templo de la c/Holguín se puede explicar por el hecho de que se trate de un templo dedicado al culto imperial, mientras que el Foro de mármol, al contrario de lo que se venía pensando debido a su semejanza con el Foro de Augusto en Roma, ${ }^{57}$ parece haber sido el sitio de homenaje a las personalidades locales. ${ }^{58}$

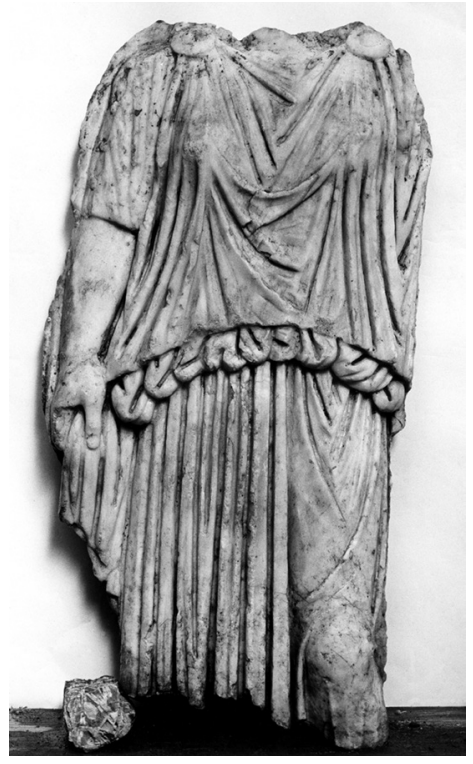

Fig. 7. Mérida. Cariátide del Foro de mármol de la c/ Sagasta, actualmente fechada en época flavia. Inst.-Neg. IAA Madrid R 23-86-11 Foto (P. Witte).

Un problema aparte lo constituye la escultura perteneciente a estos edificios, que Trillmich ha analizado en diversos estudios de modo ejemplar. ${ }^{59}$ Contiene múltiples referencias a la ciudad de Roma, de modo que Augusta Emerita desde siempre se calificó como la "Roma española". ${ }^{60}$ Sin embargo, a lo largo de la investigación, las fechas se han ido avanzando, de manera que lo que parecía ser de época augustea, como el citado Foro de mármol de la c/Sagasta ahora resulta ser flavio (Fig. 7). Con ello se pone de manifiesto que la gama de formas augusteas también se continuó utilizando hasta muy entrada la época flavia. Queda por saber dónde se encontraba colocada la escultura datada en época augustea que Trillmich representó con detalle.

\footnotetext{
56 Stylow - Ventura VillanueVa 2009, 521.

57 Trillmich 1990, 312; Álvarez Martínez - Nogales Basarrate 2003, 316-322.

58 Stylow - Ventura Villanueva 2009, 521. 523.

59 Visión de conjunto en Trillmich 1990, 310-316.

60 SCHulten 1922, 1.
} 


\section{Los ejemplos de Conimbriga y Munigua como ciudades romanas superpuestas a poblados indígenas}

Como ejemplos del establecimiento de una ciudad romana en un asentamiento autóctono preexistente pueden servir las ciudades de Conimbriga en Lusitania y Munigua en la Bética. En Conimbriga, las excavaciones franco-portuguesas en la década de 1970 mostraron que en el punto más alto de la ciudad se demolió un barrio de viviendas autóctono para construir allí el foro augusteo ${ }^{61}$ Este foro estaba construido sobre un podio situado a $1,70 \mathrm{~m}$ sobre el nivel del suelo y se accedía por una escalera. Es interesante recordar que el foro poseía tanto una curia como una basílica en un momento en el que Conimbriga todavía no tenía ningún estatus jurídico adecuado. Este foro augusteo coexistió con el asentamiento autóctono ("coéxistence augustéenne") hasta la época flavia. ${ }^{62}$ Dado que el templo del foro tenía $13 \mathrm{~m}$ de altura, se tiene una idea de la impresión que esta edificación debía causar en los habitantes, acostumbrados sólo al tamaño de las casas de una sola habitación. En la época flavia no sólo surgió un nuevo foro, ${ }^{63}$ sino que para entonces muchas casas privadas de Conimbriga habían adoptado el estilo arquitectónico romano. ${ }^{64}$

En Munigua, sin embargo, hasta la fecha no se puede designar ninguna edificación claramente atribuible a la época de Augusto. Fundada probablemente en el siglo IV a.C. en lo alto del cerro municipal, ${ }^{65}$ las laderas empezaron a servir de terreno para la construcción a partir de época julio-claudia, ${ }^{66}$ amortizándose así el área que se había caracterizado por sus instalaciones para trabajos metalúrgicos y de fundición de metal, especialmente de cobre.$^{67}$ Esa amortización, sin embargo, señala un cambio en la utilización del espacio urbano en el sentido de una conversión: el espacio industrial ahora es terreno para construcción de edificios públicos y de viviendas. Es tentador conectar ese hecho con el correspondiente y famoso Tratado de Hospitalidad fechado en época de Augusto o Tiberio. ${ }^{68}$ En el mismo momento arranca la minería de cobre muniguense en las mismas minas del hinterland. ${ }^{69}$ El poblado en altura ("poblado ibérico"), situado sobre lo alto del cerro municipal, es tema de estudios futuros, hasta ahora sólo se ha procedido a un sondeo mediante el cual se descubrieron restos del citado habitat del siglo I a.C. avanzado. Actualmente, el edificio público más antiguo

61 Alarcão - ÉtienNe 1977, 27-39 lám. 11.

62 Alarcão - ÉtienNe 1976, 177-179.

63 AlarCão - ÉtienNe 1977, 85-112 lám. 12; posteriormente se discutió la distribución de las fases, reconociéndose tres, véase RORTH-CONGÈs 1987, 725-728, lo que produjo una controversia interesante, véase ALARCÃo - ÉTIENNE - Golvin 1997; CORREIA 2004, que se encuentra en espera a falta de nuevos datos. Actualmente, el debate gira en torno a los otros edificios que pueden haber asumido el cumplimiento de las funciones del foro a partir del momento en el que el templo pasa a ser dedicado al culto imperial, CORREIA 2010, 91.

64 Bonita ilustración en Golvin 2006, 127 ss.

65 SCHATTNER 2006, 43-50.

66 SCHATTNER 2014.

67 Mapa correspondiente en PÉrez Macías - SCHATtNer 2013, 254 fig. 12.

68 Todas las dataciones propuestas expuestas en SCHATTNER 2013, 271, n. 2.

69 Pérez Macías - SchattNer 2013, 252. 
conocido es el de las termas de época claudia (Fig. 8), ${ }^{70}$ datadas por las monedas como terminus ante quem. ${ }^{71}$

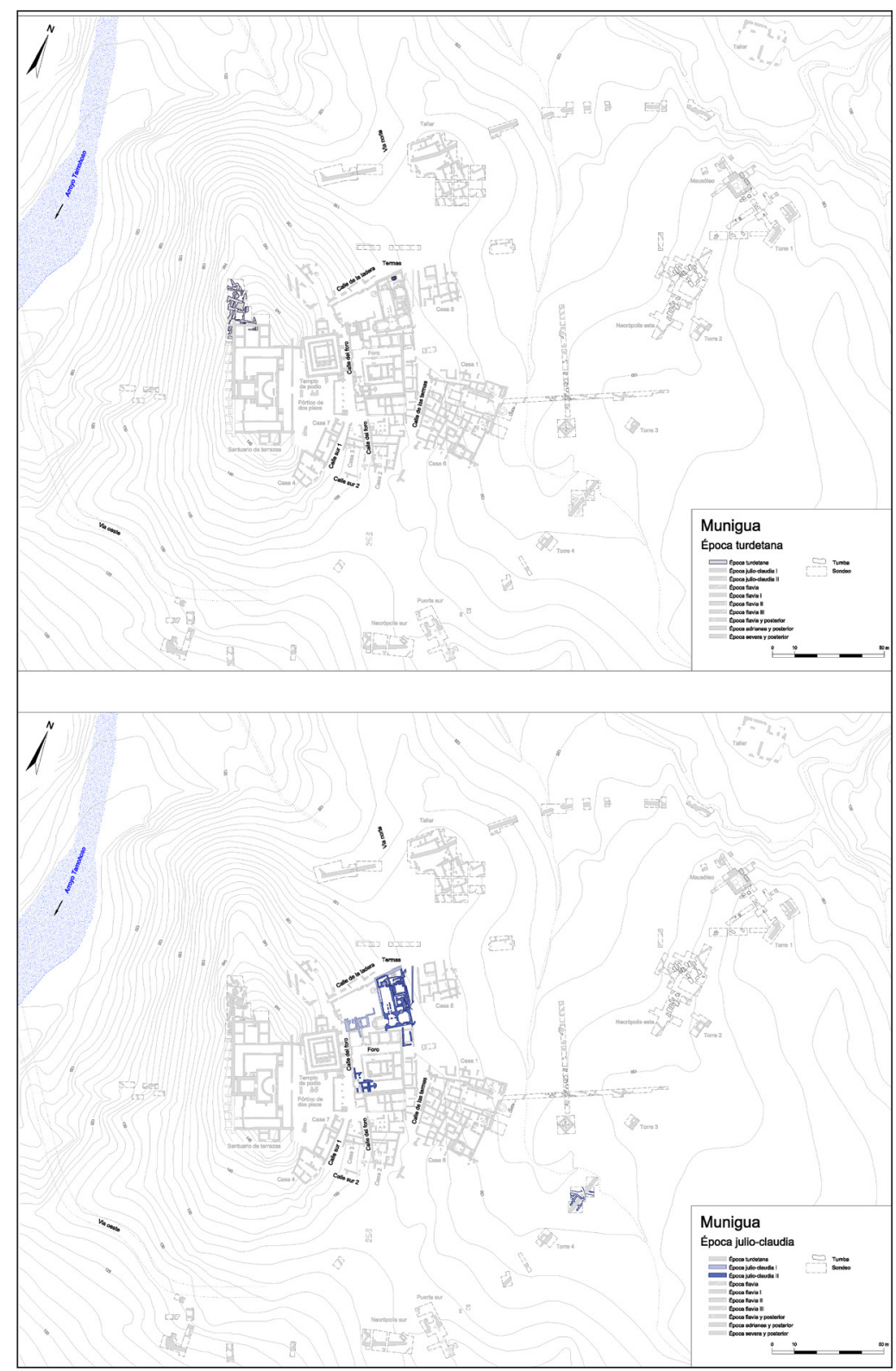

Fig. 8. Munigua. Las fases turdetana y julio-claudia. IAA de Madrid (D. Schäffler).

70 Schattner - Basas Fauré 2006, 142.

71 Chaves Tristán 2006. 
Resumiendo, la exposición de los ejemplos de Augusta Emerita, Conimbriga y Munigua muestra muy claramente el continuado proceso constructivo en el que se encontraban las ciudades a partir de la época augustea (Augusta Emerita, Conimbriga) o augustea-tiberiana-claudia (Munigua). Parece que los planos de ordenación y parcelación territorial y espacial intramuros estaban establecidos, y que se había comenzado a construir algunos edificios. Además, al mismo tiempo debe de haber habido muchas parcelas disponibles reservadas para futuras construcciones. En relación con el estado anterior, ese arranque y consecuente cambio de las ciudades o poblaciones parece ser el elemento caracterizador de la época de Augusto, tanto en las nuevas fundaciones como en las ciudades superpuestas. Sin embargo, pocas de las obras comenzadas se acabarían dentro de un periodo de tiempo corto, la mayor parte de ellas se mantuvieron en proceso de construcción. Parece haber un lapso de tiempo considerable entre la planificación de la obra, su ejecución y su finalización. Siendo así, las ciudades en toda regla deben de haber presentado un aspecto inacabado, en construcción hasta la época flavia, cuando parece haberse llegado a un cierto punto de finalización. La observación de la existencia de ese largo proceso de construcción y de la ciudad inacabada no es un elemento nuevo en la investigación, ya es conocido desde hace bastante tiempo, como se expondrá en el párrafo siguiente.

\section{Repaso historiográfico}

En la investigación dedicada a las ciudades y a sus monumentos ha prevalecido desde siempre, y a lo largo del tiempo, la idea de la ciudad acabada. Todavía las ilustraciones maravillosas de J.-C. Golvin, editadas en nuestros días, pecan de ello. ${ }^{72}$ Para la fundación y la planta original de Augusta Emerita es A. Schulten quien supone por primera vez en 1922, en un artículo llamado "Mérida, das spanische Rom" una planificación definida y programática, aplicando por vía analógica los modelos de las ciudades de Augusta Taurinorum (Torino) y Augusta Praetoria (Aosta) en Italia, ambas de planta cuadrada o ligeramente rectangular siguiendo con ello la forma de un campamento militar. ${ }^{73} \mathrm{La}$ analogía consiste en que ambas son colonias, tal como Augusta Emerita, de modo que Schulten concluye que éste es el modelo de planta de ciudad correspondiente, ya que además la reconoce en la colonia militar de Thamugadi. Mientras que en estas ciudades de Italia prevalece un módulo de 2400 x 2400 pies equivalente a $700 \times 700 \mathrm{~m}$, en la ciudad norteafricana el módulo es la mitad, es decir 350 m, equivalente a 1200 pies romanos, equivalente a 10 actus. En Mérida, Schulten observa esa medida de $350 \mathrm{~m}$ en la distancia entre las dos entonces supuestas puertas de la ciudad, el Arco de Trajano al Norte y una puerta desaparecida, que se tendría que encontrar en el cruce de las calles Bastimentos y Abalos/Cimbrón, al Sur. ${ }^{74}$ Este cuadrilátero de $350 \times 350 \mathrm{~m}$ sería ampliado en épocas posteriores en las direcciones

72 Golvin 2006.

73 Las plantas, p. ej. en Pfanner 1990, 87.

74 La idea está tomada de la publicación de M. Macías Liáñez, Mérida monumental y artística, $1^{\mathrm{a}}$ ed. de 1913, y 2a ed. de 1929 (MacíAs LiáÑEZ 1929, 67). 
$\mathrm{N}$ y S, dándole la forma actual de la ciudad, lo que Schulten determina con $2400 \mathrm{x}$ 2400 pies $(700 \times 700 \mathrm{~m}) .^{75}$

Las ideas de Schulten fueron publicadas en el periódico alemán para España (Deutsche Zeitung für Spanien), de modo que pocos años después, en 1925, J. R. Mélida las difundió en el ámbito científico de la Península, considerándolas bien fundadas y válidas. ${ }^{76}$ La observación de que el Arco de Trajano no fue, ni mucho menos, la Puerta Norte de la ciudad se debe al arqueólogo inglés I. A. Richmond, ${ }^{77}$ quién en el año 1930 publicó un destacado artículo sobre la capital de Lusitania. Este autor muestra una buena capacidad de observación, describe los edificios y su evolución, es decir, si se superponen unos a otros, si se adosan, etc. y juntamente con observaciones de orden técnico, como el uso de ladrillo o de mortero, o de orden estático, sobre la distribución de los pesos, establece un listado de 11 edificios fundacionales de primera época, cuyos límites cronológicos son los años 23 a.C. por un lado, y 16 a.C. respectivamente 8 a.C. por el otro. ${ }^{78}$ De este modo, para Richmond, la Colonia Augusta Emerita se habría construido en esos 15 años, desde el diseño del plano original de la ciudad (lay-out) con las cloacas, pasando por los Puentes del Guadiana y del Albarregas hasta sus construcciones aledañas, incluyendo la red viaria, las murallas y los acueductos de Cornalvo, Los Milagros y San Lázaro, el anfiteatro y el circo. Con todo ello en pie habría que suponer que también las casas particulares lo estuvieron de una forma u otra, y que de esta manera Augusta Emerita sería una ciudad acabada de construirse en ese momento.

Ese planteamiento se mantuvo vigente durante mucho tiempo. A. García y Bellido, en su obra general sobre la urbanística en el mundo antiguo de 1966, obra de referencia en lengua española ${ }^{79}$ tiene su punto de partida metodológico en la ciudad acabada, no llegando a plantear la cuestión. Desde luego que las ciudades y poblados que describe son siempre obras acabadas.

Un hito en el avance de la investigación lo constituyen dos importantes coloquios, ambos del año 1976, ambos dedicados a dos grandes ciudades hispánicas, Augusta Emerita y Caesaraugusta/Zaragoza. ${ }^{80}$ Para Mérida el coloquio significó el punto de partida de un desarrollo impresionante que vivió la arqueología emeritense, y ello gracias al esfuerzo común de todas las partes. ${ }^{81}$ Desde entonces hasta hoy las excavaciones e investigaciones alcanzaron una velocidad de vértigo, lo que significa una actualización de la investigación muy rápida y repentina, a través de la cual se consigue por primera vez matizar la lista de Richmond. Sin embargo, con relación al problema que aquí nos ocupa, es decir, la fundación de la ciudad y el proceso de finalización de la misma, en el coloquio Bimilenario de 1976 se seguía manteniendo el esquema

75 SCHULten 1922

76 MÉLIDA 1925, 119 ss.

77 Richmond 1930, pero ya Macías LiáÑEz 1929, 67.

78 Richmond 1930, 114.

79 Desde la investigación internacional, sin embargo, se consideró que no aportaba nada nuevo, GrECo TORELLI 1983 en su capítulo historiográfico.

80 F. BlanCo FreiJeIro 1976a; 1976 b.

81 Mateos Cruz 2001, 183-186. 
del erudito inglés. ${ }^{82}$ Por otro lado, en el volumen dedicado a Caesaraugusta, Balil expone los novedosos resultados de sus investigaciones sobre las ciudades romanas, rompiendo con los estereotipos. Expone las dificultades que las ciudades tuvieron para levantar los edificios, describe la trayectoria de una construcción que se inicia en época augustea, pero que después se prolonga mucho en el tiempo y acaba finalizándose en época flavia o incluso en el siglo II d.C. ${ }^{83}$ Con respecto a las ciudades hispanas en general constata que el equipamiento de las mismas con edificios públicos fue muy parco en la época augustea. ${ }^{84}$

Más recientemente Trillmich y Zanker, en el prefacio -que en realidad es la conclusión del encuentro- del famoso coloquio madrileño sobre "Stadtbild und Ideologie" hacen un intento por observar en las ciudades de la Península el nuevo programa ideológico y simbólico augusteo. Los elementos clave para ellos son la aplicación del nuevo lenguaje iconográfico augusteo y su materialización en mármol en toda Hispania. ${ }^{85}$ En el caso de la Colonia Augusta Emerita utilizan el mencionado catálogo de monumentos de Richmond como base para su argumentación. ${ }^{86}$

\section{Valoración}

Aunque las bases arqueológicas para las dataciones de época augustea en Augusta Emerita sean limitadas, no cabe duda del valor de las correspondientes inscripciones que prueban de forma clara la existencia del teatro y del anfiteatro en ese momento, aunque posiblemente no hayan estado terminados del todo, pero si utilizables y quizás incluso inaugurados. Así lo indica el examen epigráfico de forma contundente. Que un monumento iniciado por un emperador quede sin finalizar a su muerte, de modo que su sucesor se ocupe de terminarlo, tiene como ejemplo el Puente de Ariminum/Rimini, obra de Augusto que Tiberio inauguró. ${ }^{87}$

M. Horster, que trabajó largamente sobre las actuaciones edilicias de los emperadores tanto desde una base epigráfica como literaria, no duda en incorporar los correspondientes testimonios literarios y las correspondientes inscripciones en sus análisis. ${ }^{88}$ Estos documentos dan fe de las cuatro siguientes implicaciones edilicias o financieras del propio Augusto en Hispania:

1) Considerables montantes de dinero para diversas regiones en Galia, Germania e Hispania en los años 16-14 a.C. (Dio, 54.25.1).

82 Álvarez Sáenz de Buruaga 1976, 20-27.

83 BALIL 1976, 32.

84 BaLIL 1976, 65-68.

85 ZANKer 1990.

86 Para el estado actual de la investigación sobre los monumentos listados por Richmond, véase Mateos Cruz 2001; Mateos Cruz 2004 y Mateos Cruz - Palma García 2004.

87 Dessau 1924, n 84. 133. 113.

88 HORSTER 1997, 114 (tabla): donación de grandes sumas de dinero para diversas regiones; Horster 2001, 348 cat. XIV 2,1 (anfiteatro de Augusta Emerita). 
2) Anfiteatro de Augusta Emerita en el año 8/7 a.C. ${ }^{89}$

3) Muralla, torres y puertas de la Colonia Pax Iulia/Beja el día 5 de febrero del año 2 a.C. ${ }^{90}$

4) Arquitrabe y tal vez el Santuario de Asclepios en la civitas Bracara Augusta. ${ }^{91}$

Estas donaciones no son de ningún modo excepcionales sino todo lo contrario, se incorporan perfectamente en la política edilicia seguida por el primer princeps, quién animó de forma expresa a sus familiares y amigos para que también ellos se convirtieran en benefactores de las nuevas ciudades, ${ }^{92}$ que empezaban a despuntar en todo el imperio en ese momento, donando edificaciones no sólo en Roma, sino también en las provincias. Este prolongamiento u extensión hacia las provincias es una actuación totalmente nueva, antes desconocida, iniciada por César, pero continuada a mayor escala por Augusto. ${ }^{93}$ Concretamente, como paralelo para Augusta Emerita, cabe mencionar que Agripa ya antes había donado un teatro en Ostia en el año 27 a.C. ${ }^{94}$ que Augusto había dedicada otro en Laodikeia/Asia Menor, ${ }^{95}$ y que antiguos oficiales del ejército dedicaron asimismo un anfiteatro en Luceria en honor de Augusto. ${ }^{96}$ Murallas, torres y puertas también fueron donados por Augusto en las colonias de Vienne y Nemausus. ${ }^{97}$

Kienast, en su famoso libro sobre Augusto, escribe todo un capítulo sobre la política edilicia del primer Princeps, capítulo que en muchas de sus 41 páginas recoge listados de edificios dedicados por éste. ${ }^{98}$ De ello resulta que se puede esperar la beneficencia de Augusto y de su familia allí donde éstos sean llamados para asumir altos cargos públicos, o incluso a ser patronos municipales como en Caesaraugusta, Carthago Nova, Gades, Italica, Salaria o Ulia, o en ciudades capitales que lleven su nombre, lo que significa un privilegio especial, ${ }^{99}$ como es el caso de la Colonia Augusta Emerita ${ }^{100}$ Resumiendo, el hecho de encontrar dedicaciones imperiales en Augusta Emerita no es causa de asombro, y está directamente relacionado con la política edilicia seguida por Augusto.

A la hora de realizar una donación se suele admitir un criterio programático o planificador. Sin duda que el mismo Augusto se implicaba en el sentido de que se interesaba, de una manera $u$ otra, pero sin entrar en ningún tipo de detalles. ${ }^{101} \mathrm{La}$ ob-

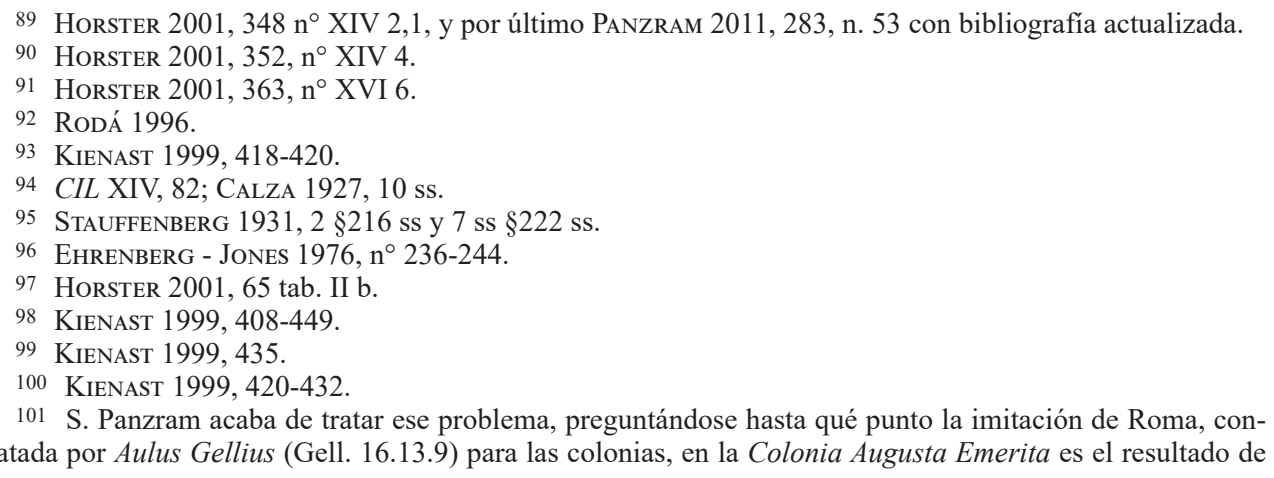


servación conlleva a su vez la afirmación de una planificación central, llevada a cabo posteriormente, in loco, por medio de personal especializado y seguramente con la ayuda del ejército. ${ }^{102}$ Posiblemente, el interés del primer Princeps se haya limitado a controlar la función del monumento como signo de poder, lo que se explica a continuación, ya que el efecto de estos signos era bien conocido en Roma. ${ }^{103}$

Por lo expuesto, las ciudades de Hispania debieron de conservar en gran medida su rostro hispánico autóctono durante la época de la República hasta bien entrada la época imperial. Del análisis de los mapas de distribución del párrafo A se entiende claramente que Augusto no tenía la pretensión de llenar todo el territorio hispano sistemáticamente con ciudades. Lo que sí se observa es una intervención planificada en algunas regiones, conforme vimos en la baja Lusitania o en el valle del Ebro. Augusto sí promueve el establecimiento de signos de poder bien visibles en algunas ciudades selectas o puntos específicos. Conimbriga es un ejemplo perfecto para entender la política augustea de construcción y colonización en ese sentido en Hispania. El foro augusteo conimbricense es un signo de poder. Sus características básicamente son las siguientes: situación en un punto clave del entorno (esto es: el centro de la ciudad), tamaño, visibilidad, riqueza (mármol, color, decoración arquitectónica, estatuas, accesorios y otros), accesibilidad y funcionalidad. En el caso del templo de la c/Holguín en Augusta Emerita se añadiría el criterio de la rapidez en su ejecución, solo cinco años, ya que es un elemento distintivo.

Los signos de poder son las manifestaciones materiales del Imperio romano, especialmente en las provincias. ${ }^{104}$ Son, en el caso que aquí nos interesa, arquitectura, monumentos, edificios. ${ }^{105}$ Permiten una percepción del espacio basada en su enumeración, sin tener que recurrir a mapas. Entendiendo el concepto de signo de poder/ landmark en este sentido, quedaría definido el trayecto del Foro de Conimbriga al Faro de La Coruña por el simple hecho de mencionar esos dos enclaves. De no existir esos monumentos, no existirían los nombres, y de no existir los nombres, ¿cómo señalaríamos esos sitios? Para Roma era importante señalar sitios en los territorios conquistados para así poder darles un nombre latino y de esta manera poder pronunciar$10^{106}$ y conectarlo mentalmente con el mundo romano. Por eso, para poder dominar una región, era indispensable hacer esa región accesible para los romanos por medio de la señalización de nombres de monumentos dispersos en el territorio, y que además fuesen pronunciables. De este modo se explica el porqué de añadir a los nombres indígenas otro nombre romano, como en el caso de Ebora o Corduba por ejemplo. ${ }^{107}$

un deseo del poder central en Roma, o más bien una forma de los locales de compartir los modelos de la urbs, llegando a afirmar, y con razón, la opción mencionada por último (PANZRAM 2011).

102 Kienast 1999, 423-426.

103 BRodersen 1995.

104 Brodersen 1995.

105 Para otros signos de poder como textos, símbolos o imágenes, véase Brodersen 1995, 112-137.

106 Véase en este contexto la afirmación de Plinio, quién en la introducción a su geografía de África dice que los nombres de sus pueblos y sus poblaciones son impronunciables, excepto en sus propias lenguas ( $\mathrm{NH}$ $5.1)$.

107 Como señala GALSTERER-KRÖLL 1972, 86 es especialmente la región africana, la que destaca por ofrecer el mayor número de nombres latinos añadidos a los nombres indígenas de las ciudades. 
Los signos de poder/landmarks actúan para en ambas direcciones: para los habitantes indígenas señalan la presencia de Roma como nueva potencia dominadora mediante un monumento físicamente existente, capaz de enaltecer el nuevo orden, siendo al mismo tiempo de una forma u otra útil, accesible y funcional. Para los romanos los signos de poder son un medio para entender mentalmente la extensión del Imperio. Estos signos de poder pueden ser monumentos, aunque también símbolos o textos. Las arae sestianae, como las columnas de Hércules, son principalmente signos de poder que permiten referirse a los puntos extremos de la extensión del mundo en el discurso de un romano. El faro romano de La Coruña no sólo iluminaba el camino a los navegantes, sino que era, al mismo tiempo, una referencia cartográfica sin la necesidad de la existencia de un mapa. De esta manera, los signos de poder/landmarks sirven como medio cartográfico sin serlo. ${ }^{108}$ Porque una cosa es que los agrimensores midan el terreno, delimitando zonas, definiendo parcelas y proyectando caminos y vías, es decir, conceptualizando el territorio, y otra es entender la inmensa extensión del Imperio romano. ${ }^{109}$

Todo este proceso en su conjunto es lento. La gran potencia que es Roma se va mostrando paulatinamente en la estructura de las ciudades, desde luego mucho más despacio de lo que avanza la propia romanización en las cabezas de las personas. Las diferentes velocidades en los distintos medios de avance de la romanización es algo conocido, compárese la rapidez de circulación de las monedas con el tiempo de construcción de un edificio, por ejemplo. Al contrario de los casos descritos de Augusta Emerita y Conimbriga, en las pequeñas ciudades de provincia como Munigua, no está nada clara la forma bajo la cual Roma se manifestaba físicamente en la primera época imperial. Seguramente a través de su administración, y en otros lugares a través de sus militares, allí donde estos tuvieran sus campamentos, que son pocos. En los asentamientos en llano de nueva construcción es la planta de la ciudad misma la que indica la presencia de Roma, la actitud constructiva permanente en las capitales, como Augusta Emerita, la aumenta. En ésta última, después de delimitar el área, se realizó la retícula urbana con la canalización y el sistema de calles, y se construyó el puente y el dique de contención. En esos primeros edificios la construcción se basaba en sillares de granito estucado. Como ese material se encuentra asimismo en el Templo de Diana, no hay duda de su contemporaneidad. ${ }^{110} \mathrm{Y}$ augusteos parecen ser también los cimientos de la gran edificación al sur de la ciudad, en la c/John Lennon. ${ }^{111}$ En suma, durante la época de Augusto, la política edilicia estatal romana no consistía en un mero laisser faire, ${ }^{112}$ sino que contenía elementos programáticos de planificación, como se ha podido demostrar.

108 BRODERSEN 1995, 112-116. Especialmente sobre las arae sestianae en este sentido recientemente GRÜNER 2005.

109 Bendlin 1997, 37.

110 Álvarez Martínez 1976, 50; Nogales Basarrate 2003; por último Panzram 2011, 283.

111 Mateos Cruz 2001, 195.

112 Sobre el término MaRín DíAz 1980. 


\section{BibLIOGRAFÍA}

Alarcão, J. - Étienne, R.

(1976): "Le Portugal à l'époque augustéenne" [en] Ciudades augusteas de Hispania I. Bimilienario de Zaragoza, symposion de ciudades augusteas, Zaragoza, 5-9 de octubre de 1976, Zaragoza, 171-188.

(1977): Fouilles de Conimbriga. 1 L'architecture, Paris.

Alarcão, J. - Étienne, R. - Golvin, J.-C. (1997): "Le centre monumental du Forum de Conimbriga. Réponse à quelques contestations", [en] R. Étienne - F. Mayet (eds.), Itinéraires lusitaniens: trente années de collaboration archéologique luso-française. Actes de la réunion tenue à Bordeaux les 7 et 8 avril 1995 à l'occasion du trentième anniversaire de la Mission Archéologique Française au Portugal, Paris, 49-70.

Álvarez Martínez, J. M.

(1976): "El Templo de Diana", [en] F. Blanco Freijeiro (coord.), Augusta Emerita. Actas del simposio internacional conmemorativo del Bimilenario de Mérida, 16 - 20 de Noviembre de 1975, Madrid, 43-53.

(1983): El puente romano de Mérida (Monografías Emeritenses 1), Badajoz.

(2006): "Los accesos al recinto de la Colonia Augusta Emerita, la Puerta del Puente", [en] Th. G. Schattner - F. Valdés Fernández (eds.), Stadttore - Bautyp und Kunstform. Puertas de ciudad - tipo arquitectónico y forma artística, Actas del coloquio en Toledo del 25 al 27 de septiembre 2003 (Iberia Archaeologica 8), 221-251.

Álvarez Martínez, J. M. - Nogales Basarrate, T. (2003): Forum Coloniae Augustae Emeritae “Templo de Diana”, Mérida.

Álvarez Sáenz de Buruaga, J. (1976): "La fundación de Mérida", [en] F. Blanco Freijeiro (coord.), Augusta Emerita. Actas del simposio internacional conmemorativo del Bimilenario de Mérida, 16 - 20 de Noviembre de 1975, Madrid, 19-30.

BALIL, A. (1976): "Las ideas urbanísticas en época augustea", [en] Ciudades augusteas de Hispania I. Bimilenario de Zaragoza, symposion de ciudades augusteas, Zaragoza, 5-9 de octubre de 1976, Zaragoza, 29-78.

Bendala Galán, M. (1990): "El plan urbanístico de Augusto en Hispania”, [en] W. Trillmich - P. Zanker (eds.), Stadtbild und Ideologie. Die Monumentalisierung hispanischer Städte zwischen Republik und Kaiserzeit, Coloquio en Madrid, 19-23 de octubre de 1987, München, 25-42.

Bendala Galán, M. - Durán, R. (1994): “El anfiteatro de Augusta Emerita. Rasgos arquitectónicos y problemática urbanística y cronológica”, [en] J. M. Álvarez Martínez - J. J. Enríquez Navascués (eds.), El anfiteatro en la Hispania romana. Coloquio internacional del Bimilenario del Anfiteatro romano de Mérida, Mérida 1992, Mérida, 247-264.

Bendala Galán, M. - Fernández Ochoa, C. - Fuentes Domínguez, A. - Abad Casal, L. (1987): “Aproximación al urbanismo prerromano y a los fenómenos de transición y de potenciación tras la conquista", [en] Los asentamientos ibéricos ante la romanización, Coloquio Madrid, 27-28 de febrero de 1986, Madrid, 121-140.

Bendlin, A. (1997): "Peripheral centres - central Peripheries: religious comunication in the Roman Empire”, [en] H. Cancik - J. Rüpke (eds.), Römische Reichsreligion und Provinzialreligion, Tübingen, 35-68. 
Blanco FreijeIro, F. (coord)

(1976a): Augusta Emerita. Actas del simposio internacional conmemorativo del Bimilenario de Mérida, 16 - 20 de Noviembre de 1975, Madrid,

(1976b): Ciudades augusteas de Hispania I. Bimilienario de Zaragoza, Symposion de ciudades augusteas, Zaragoza, 5-9 de octubre de 1976, Zaragoza.

Blázquez, J. M. (1976): “Ciudades hispanas de la época de Augusto”, [en] Ciudades augusteas de Hispania I. Bimilienario de Zaragoza, symposion de ciudades augusteas, Zaragoza, 5-9 de octubre de 1976, Zaragoza, 79-136.

Blázquez Martínez, J. M. - Domergue, C. - Sillières, P. (2002) (eds.): La Loba (Fuenteobejuna, province de Cordue, Espagne). La mine et le village minier antiques (Ausonius Mémoires 7), Bordeaux.

Bleicken, J. (1967): s. v. Imperium, 1382 ss, [en] Der Kleine Pauly 2, Stuttgart.

BOATWRIGHT, M.

(1997): "Italica and Hadrian's urban benefactions", [en] A. Caballos (ed.), Italica MMCC. Actas de las Jornadas del 2.200 Aniversario de la Fundación de Italica, Sevilla, 115-135. (2000): Hadrian and the Cities of the Roman Empire, Oxford.

Brodersen, K. (1995): Terra cognita. Studien zur römischen Raumerfassung (Spudasmata 59), Hildesheim.

Burillo Mozota, F. (2007): Los celtíberos. Etnias y estados, Barcelona, (ed. actualizada).

Calza, G. (1927): Il teatro romano di Ostia, Roma-Milano.

Cebbrián SÁnchez, M. Á. (2008): "La fundación de la Colonia Augusta Emerita y la nueva política monetaria”, [en] Ma . P. García-Bellido - A. Mostalac - A. Jiménez (eds.), Del Imperium de Pompeyo a la Auctoritas de Augusto, Homenaje a Michael Grant (= Anejos AEspA 47), 243-249.

Chaves Tristán, F. (2006): "Las monedas”, [en] Th. Schatter-C. Basas Fauré, 136 ss.

Correia, V. H.

(2004): "Coexistência e revolução. Urbanismo e arquitectura em Conimbriga (séc. I a.C.III d.C.)", [en] M. C. Lopes - R. Vilaça (coords.), O passado em cena. Narrativas e fragmentos. Miscelânea oferecida a Jorge de Alarcão, Coimbra, 261-298.

(2010): "O forum de Conimbriga e a evolução do centro urbano", [en] T. Nogales Basarrate (ed.), Ciudad y foro en Lusitania Romana = Cidade e foro na Lusitânia Romana, Mérida, 89-105.

Corzo SÁnchez, D. R. (1976): “In finibus emeritensium”, [en] F. Blanco Freijeiro (coord.), Augusta Emerita. Actas del Simposio internacional conmemorativo del bimilenario de Mérida, 16 - 20 de Noviembre de 1975, Madrid, 217-233.

Curchin, L. A.

(1991): Roman Spain. Conquest and assimilation, London.

(2001): "Octavius in Spain (45 B.C.)", [en] L. Hernández Guerra - L. Sagredo San Eustaquio - J. M. Solana Sáinz (eds.), La Península Ibérica hace 2000 años. Actas del I Congreso Internacional de Historia Antigua, Valladolid, 23-25 de noviembre de 2000, Valladolid, 153-157.

Dessau, H. (1924): Geschichte der römischen Kaiserzeit 1, Berlin.

Durán CABello, R. M. (2004): “Edificios de espectáculo”, [en] X. Dupré Raventós (ed.), Las capitales provinciales de Hispania, 2. Mérida. Colonia Augusta Emerita, Roma, 55-66. 
EhrenberG, V. - Jones, A. H. M. (1976): Documents illustrating the reigns of Augustus and Tiberius, Oxford.

GALSTERER, H. (1971): Untersuchungen zum römischen Städtewesen auf der Iberischen Halbinsel (Madrider Forschungen 8), Berlin.

GALSTERER -KRÖLL, B. (1972): “Untersuchungen zu den Beinamen der Städte des Imperium Romanum", [en] Epigraphische Studien, Sammelband (Epigraphische Studien 9), Bonn, 44-145.

GARCÍA Y BELlido, A.

(1959): Las colonias romanas de Hispania, Madrid.

(1966): Urbanística de las grandes ciudades del mundo antiguo, Madrid.

Golvin, J.-C. (2006): Metropolen der Antike, $3^{\text {a }}$ ed., Stuttgart (= L'antiquité retrouvée, Paris 2003).

Greco, E. - Torelli, M. (1983): Storia dell urbanistica, Roma.

Griepentrog, M. (1991): “Munigua 1989. Die Grabung in der Heiligtumsterrasse”, Madrider Mitteilungen 32, 141-152.

GRÜNER, A.(2005): “Die Altäre des L. Sestius Quirinalis bei Kap Finisterrae”, Madrider Mitteilungen 46, 247-266.

HORSTER, M.

(1997): Literarische Zeugnisse kaiserlicher Bautätigkeit. Eine Studie zu Baumaßnahmen in Städten des Römischen Reiches während des Prinzipats (Beiträge zur Altertumskunde 91), Stuttgart-Leipzig.

(2001): Bauinschriften römischer Kaiser. Untersuchungen zu Inschriftenpraxis und Bautätigkeit in Städten des westlichen Imperium Romanum in der Zeit des Prinzipats (Historia Einzelschriften 157), Stuttgart.

KIEnASt, D. (1999): Augustus, Prinzeps und Monarch, $3^{\mathrm{a}}$ ed., Darmstadt.

Koch, M. (1993): “Animus...Meus...Praesagit, Nostram Hispaniam Esse”, [en] A. NünnerichAsmus - W. Trillmich - Th. Hauschild - M. Blech (eds.), Hispania Antiqua. Denkmäler der Römerzeit, Mainz am Rhein, 1-40.

LAFFI, U. (2002): “La colonización romana desde el final de la guerra de Aníbal a los Gracos”, [en] J. L. Jiménez Salvador - A. Ribera i Lacomba (eds.), Valencia y las primeras ciudades romanas de Hispania, Valencia, 19-26.

MacíAs LiÁÑEZ, M. (1929): Mérida monumental y artística, $2^{\mathrm{a}}$ ed., Barcelona (1 ${ }^{\mathrm{a}}$ ed. de 1913, non vidi).

MARÍN DíAz, N. (1980): "Sobre el uso incorrecto del término laisser faire, laisser passer en la antigüedad", Memorias de Historia Antigua 4, 19-26.

Mateos Cruz, P.

(2001): “Augusta Emerita. La investigación arqueológica en una ciudad de época romana”, AEspA 74, 183-200.

(2004): “Topografía y evolución urbana”, [en] X. Dupré Raventós (ed.), Las capitales provinciales de Hispania, 2. Mérida. Colonia Augusta Emerita, Roma, 27-39.

Mateos Cruz, P. - MÁrquez, J. (1999): "Nuevas estructuras urbanas relacionadas con el teatro romano de Mérida", Mérida. Excavaciones arqueológicas. Memoria 3, 301-320. 
Mateos Cruz, P. - Palma García, F. (2004): “Arquitectura oficial”, [en] X. Dupré Raventós (ed.), Las capitales provinciales de Hispania, 2. Mérida. Colonia Augusta Emerita, Roma, 41-53.

MÉLIDA, J. R. (1925): Catálogo monumental de España, provincia de Badajoz (1907-1910), Madrid.

Millar, F. (1988): "Imperial ideology in the Tabula Siarensis", [en] J. González - J. Arce (eds.), Estudios sobre la Tabula Siarensis (=Anejos AEspA 9), Madrid, 11-19.

MorA, G. (2004): “Historia de la investigación”, [en] X. Dupré Raventós (ed.), Las capitales provinciales de Hispania, 2. Mérida. Colonia Augusta Emerita, Roma, 15-26.

Nogales Basarrate, T. (2003): "Colonia Augusta Emerita (Mèrida) von der Granitstadt zur Marmorstadt", [en] Die Stadt als Großbaustelle von der Antike bis zur Neuzeit, Internationaler Kongre $\beta$ vom 7. bis 11. November 2001, Berlin, 82-87.

NÜNNERICH-Asmus, A. (1993): "Straßen, Brücken und Bögen als Zeichen römischen Herrschaftsanspruchs", [en] A. Nünnerich-Asmus - W. Trillmich - Th. Hauschild - M. Blech (eds.), Hispania Antiqua. Denkmäler der Römerzeit, Mainz am Rhein, 121-157.

PANZRAM, S. (2011): "Monumentalisierung römischer Macht - augusteische Stadtanlagen zwischen >Monotonisierung < und imitatio Urbis", [en] G. Moosbauer - R. Wiegels (eds.), Fines imperii - imperium sine fine? Römische Okkupations- und Grenzpolitik im frühen Prinzipat. Internationaler Kongress, Osnabrück 2009 (Osnabrücker Forschungen zu Altertum und Antike-Rezeption 14), Osnabrück, 275-296.

PEÑA, A.

(2009): "La decoración arquitectónica", [en] R. Ayerbe - T. Barrientos - F. Palma (eds.), El foro de Augusta Emerita. Génesis y evolución de sus recintos monumentales (Anejos AEspA 53), Mérida, 525-582.

(2009a): "La decoración escultórica", [en] R. Ayerbe - T. Barrientos - F. Palma (eds.), El foro de Augusta Emerita. Génesis y evolución de sus recintos monumentales (Anejos AEspA 53), Mérida, 583-621.

PÉrez MacíAs, J. A. - Schattner, Th. (2013): "Retaining and Renewing. The Roman Municipium Munigua in the light of technical developments in mining in the Hispanic Southwest", [en] S. Burmeister - S. Hansen - M. Kunst - N. Müller-Scheeßel (eds.), Metal matters. Innovative Technologies and Social Change in Prehistory and Antiquity (Menschen - Kulturen - Traditionen. Studien aus den Forschungsclustern des Deutschen Archäologischen Instituts 12), Berlin, 241-260.

Pfanner, M. (1990): "Modelle römischer Stadtentwicklung am Beispiel Hispaniens und der westlichen Provinzen”, [en] W. Trillmich - P. Zanker (eds.), Stadtbild und Ideologie. Die Monumentalisierung hispanischer Städte zwischen Republik und Kaiserzeit, Coloquio en Madrid, 19-23 de octubre de 1987, München, 59-116.

Pina Polo, F.

(1993): “Existió una política romana de urbanización en el nordeste de la Península Ibérica?", Habis 24, 77-94.

(2004): "Deportaciones como castigo e instrumento de colonización durante la República romana. El caso de Hispania", [en] F. Marco Simón - F. Pina Polo - J. Remesal Rodríguez (eds.), Vivir en tierra extraña. Emigración e integración cultural en el mundo antiguo, Coloquio de Historia Antigua. Actas de la reunión realizada en Zaragoza los días 2 y 3 de junio de 2003 (Instrumenta 16), Barcelona, 211-246. 
(2007): "Kontinuität und Innovation im Städtenetzwerk der nordöstlichen Iberischen Halbinsel zur Zeit der Republik", [en] S. Panzram (ed.), Städte im Wandel. Bauliche Inszenierung und literarische Stilisierung lokaler Eliten auf der Iberischen Halbinsel. Akten des Internationalen Kolloquiums des Arbeitsbereiches für Alte Geschichte des Historischen Seminars der Universität Hamburg und des Seminars für Klassische Archäologie der Universität Trier im Warburg-Haus Hamburg, 22.-22. Oktober 2005 (Geschichte und Kultur der Iberischen Welt 5), Hamburg, 25-58.

(2009): "Deportation of indigenous population as a strategy for Roman dominion in Hispania”, [en] Á. Morillo - N. Hanel - E. Martín (eds.), Limes. XX Congreso internacional de estudios sobre la frontera romana, León 2006 (Anejos de Gladius 13), Madrid, 281-288. (2010): "Las migraciones en masa y su integración en el Imperio Romano", [en] F. Javier Navarro (ed.), Pluralidad e integración en el mundo romano. Actas del II Coloquio internacional Italia Iberia, Pamplona-Olite del 15 al 17 de octubre de 2008 (Colección Mundo antiguo, n.s. 13), Pamplona, 63-80.

RODÁ, I.

(1996): "Encargos privados de monumentos públicos en Hispania”, [en] M. Mayer Olivé - M. Miró Vinaix (eds.), Committenza e commitenti tra antichità e alto medioevo. Homenatge a F. Giunta, Barcelona, 192-212.

(1997): “August. Les ciutats d'Hispania”, [en] La moneda en temps d'August, Barcelona, 9-20.

(2007): "La figura de Agrippa, el ejército y la promoción de las obras públicas en Hispania", Larouco 4, 27-43.

Richmond, I. A. (1930): “The first years of Emerita Augusta”, The Archaeological Journal 87, 98-116.

Roddaz, J. M. (1993): “Agrippa y la Península Ibérica”, Anas 6, 111-126.

Roth-CongÈs, A. (1987): “L'hypothèse d'une basilique à deux nefs à Conimbriga et les transformations du fórum”, Mélanges de l'Ecole française de Rome. Antiquité 99, 711-741.

SCHATTNER, TH.

(1999): "Die Dorfkirche von Sant'Ana do Campo. Beobachtungen an einem ungewöhnlichen römischen Tempel”, Madrider Mitteilungen 40, 189-217.

(2006): “Cerámica ática y escultura calcárea en Munigua. Formas de recepción”, [en] D. Vaquerizo - J. F. Murillo (eds.), El concepto de lo Provincial en el mundo antiguo, Homenaje a Pilar León, Córdoba, 43-53.

(2013): “¿Dónde se reunía el senado de Munigua?”, [en] Soler Huertas, B. - Mateos Cruz, P.- Noguera Celdrán, J. M. - Ruiz de Arbulo Bayona, J. (eds.), Las sedes de los Ordines Decvrionvm en Hispania. Análisis arquitectónico y modelo tipológico (= Anejos AespA 67), 271-288.

(2014): "Breve descripción de la evolución urbanística de Munigua desde sus comienzos hasta la época tardoantigua", [en] D. Vaquerizo (ed.), Ciudad y territorio: transformaciones materiales e ideológicas entre la época clásica y el Altomedioevo, Monografías de Arqueología Cordobesa 20, 2014, 293-310.

Schattner, Th. - Basas Fauré, C. (2006): "Der Kanal in der Thermengasse. Ein Beitrag zur Verfallsgeschichte der Bauten auf dem Stadthügel von Munigua", Madrider Mitteilungen 47, 104-145.

Schmitthenner, W. (1962): “Augustus'spanischer Feldzug und der Kampf um den Prinzipat”, Historia 11, 29-85. 
Schulten, A. (1922): “Mérida, das spanische Rom”, Deutsche Zeitung für Spanien 14, Barcelona (la paginación aquí citada es la del ejemplar dactilografiado existente en la biblioteca del IAA de Madrid).

Stauffenberg, A. von (1931): Die römische Kaisergeschichte bei Malalas, Stuttgart.

Stylow, A. U. - Ventura VillanueVA, Á. (2009): "Los hallazgos epigráficos", [en] R. Ayerbe - T. Barrientos - F. Palma (eds.), El foro de Augusta Emerita. Génesis y evolución de sus recintos monumentales (Anejos AEspA 53), Mérida, 453-523.

Trillmich, W. (1990): “Colonia Augusta Emerita, die Hauptstadt von Lusitanien”, [en] W. Trillmich - P. Zanker (eds.), Stadtbild und Ideologie. Die Monumentalisierung hispanischer Städte zwischen Republik und Kaiserzeit, Coloquio en Madrid, 19-23 de octubre de 1987, München, 299-318.

WAHL, J. (1985): Castelo da Lousa. Ein Wehrgehöft caesarisch-augusteischer Zeit, Madrider Mitteilungen 26, 149-176.

Weber, E. (1974): (ed.), Augustus, meine Taten. Res Gestae divi Augusti, $2^{\mathrm{a}}$ ed., Tübingen.

ZANKER, P. (1990): “Einleitung”, [en] W. Trillmich - P. Zanker (eds.), Stadtbild und Ideologie. Die Monumentalisierung hispanischer Städte zwischen Republik und Kaiserzeit, Coloquio en Madrid, 19-23 de octubre de 1987, München, 9-23. 